\title{
Overexpression of interleukin- I5 in mice promotes resistance to diet-induced obesity, increased insulin sensitivity, and markers of oxidative skeletal muscle metabolism
}

\author{
This article was published in the following Dove Press journal: \\ International Journal of Interferon, Cytokine and Mediator Research \\ 16 April 2011 \\ Number of times this article has been viewed
}

\author{
LeBris S Quinn 1,3,4 \\ Barbara G Anderson 1,3 \\ Jennifer D Conner ${ }^{2,4}$ \\ Emidio E Pistilli ${ }^{5,6}$ \\ Tami Wolden-Hanson ${ }^{1,2}$ \\ 'Geriatric Research, Education, and \\ Clinical Center, ${ }^{2}$ Research Service, \\ VA Puget Sound Health Care System, \\ Seattle, WA, USA; ${ }^{3}$ Division of \\ Gerontology and Geriatric Medicine, \\ Department of Medicine, University \\ of Washington, Seattle, WA, USA; \\ ${ }^{4}$ Seattle Institute for Biomedical \\ and Clinical Research, Seattle, WA, \\ USA; ${ }^{5}$ Department of Physiology, \\ ${ }^{6}$ Pennsylvania Muscle Institute, \\ University of Pennsylvania, PA, USA
}

Correspondence: LeBris S Quinn

S-I 82 GRECC, VA Puget Sound Health Care System, I 660 S Columbian Way,

Seattle, WA 98108, USA

$\mathrm{Tel}+\mathrm{I} 2062775552$

$\mathrm{Fax}+\mathrm{I} 2067685200$

Email quinnl@uw.edu

\begin{abstract}
Interleukin-15 (IL-15) is a cytokine that is highly expressed in skeletal muscle. In addition to its well-characterized effects on innate immunity, IL-15 has been proposed to modulate skeletal muscle and adipose tissue mass, as well as insulin sensitivity. In the present study, an IL-15 gain-of-function model, transgenic mice with skeletal muscle-specific oversecretion of IL-15 (IL-15 Tg mice), was utilized to test the hypotheses that IL-15 promotes insulin sensitivity and resistance to diet-induced obesity (DIO) by increasing circulating adiponectin levels, and that IL-15 regulates skeletal muscle metabolism without inducing overt muscle hypertrophy. Compared to closely related control mice, IL-15 Tg mice exhibited lower total body fat following high-fat feeding, lower intra-abdominal fat following both low- and high-fat feeding, and greater insulin sensitivity. However, this was not accompanied by increased total or high molecular weight serum adiponectin levels in IL-15 Tg mice. While overall lean body mass did not differ, IL-15 Tg mice exhibited increased mass of the oxidative soleus muscle, and increased expression of mRNA encoding the slow isoform of troponin I (TnnI 1) in the predominately glycolytic extensor digitorum longus muscle. Skeletal muscle tissue from IL-15 Tg mice also exhibited alterations in the expression of several genes associated with fatty acid metabolism, such as SIRT1, SIRT4, and uncoupling protein 2 (UCP2). These findings suggest changes in oxidative metabolism, rather than induction of adiponectin expression, appear to be responsible for the DIO-resistant and more insulin-sensitive phenotype of IL-15 Tg mice.
\end{abstract}

Keywords: interleukin-15, skeletal muscle, obesity, adiponectin, UCP2, sirtuins

\section{Introduction}

The increased incidence of obesity in both developed and developing nations is a major public health problem. ${ }^{1}$ Obesity is believed to be causal in the development of insulin resistance and type- 2 diabetes mellitus, conditions whose incidence is also rising at alarming rates., ${ }^{2,3}$ In addition to being a major site of energy expenditure, skeletal muscle tissue is a major site of glucose disposal. ${ }^{4}$ Age- and obesity-related reductions in muscle fatty acid oxidation result in excess intramyocellular lipid, which impedes muscle insulin sensitivity. ${ }^{4-6}$ Sarcopenia, the age-related loss of skeletal muscle, exacerbates obesity-induced insulin resistance in elderly human subjects. ${ }^{7}$ Therefore, both the muscle and fat components of body composition play important roles in determining insulin sensitivity.

In addition to central mechanisms regulating energy expenditure and food intake, peripheral factors secreted by adipose tissue (adipokines) and skeletal 
muscle (myokines) regulate body composition and insulin sensitivity. ${ }^{8,9}$ For example, tumor necrosis factor-alpha (TNF- $\alpha$ ) is a pro-inflammatory cytokine produced by adipose tissue and skeletal muscle which can induce both insulin resistance and skeletal muscle wasting. ${ }^{8,10,11}$ Circulating TNF- $\alpha$ levels are increased in diabetic and sarcopenic individuals. ${ }^{8,9,12}$ Conversely, adiponectin is an insulin-sensitizing factor primarily produced by adipose tissue, but also expressed in skeletal muscle. ${ }^{8,13}$ Adiponectin promotes glucose uptake and fatty acid oxidation in skeletal muscle. ${ }^{8,13,14}$ Adiponectin expression is inhibited by TNF- $\alpha,{ }^{15}$ and circulating levels of the high molecular weight (HMW) form of adiponectin are negatively correlated with insulin resistance and adiposity. ${ }^{8,14}$

Interleukin-15 (IL-15) is a cytokine that stimulates natural killer cytotoxic T-cells and other aspects of innate immunity. ${ }^{16,17}$ IL-15 is highly expressed in skeletal muscle tissue, ${ }^{16,17}$ and has been proposed to regulate both body composition and insulin sensitivity. ${ }^{18-25}$ In primary and immortalized murine skeletal myogenic cultures, IL-15 induces massive hypertrophy of immature skeletal muscle cells (myotubes) by modulating muscle protein synthesis and degradation rates. ${ }^{18,26}$ Additionally, in cultured primary adipocytes and adipogenic cell lines, IL-15 stimulates lipolysis and inhibits adipocyte differentiation. ${ }^{21,24,27}$ One study showed that IL-15 dose-dependently stimulated adiponectin secretion from cultured 3T3-L1 adipocytes. ${ }^{24}$ These findings suggested that muscle-derived IL-15 might function as a myokine involved in regulation of body composition in vivo, by increasing muscle mass and decreasing fat mass, and suggested that IL-15 may modulate insulin sensitivity by stimulating adiponectin expression. In fibroblasts, IL-15 can inhibit TNF- $\alpha$ signaling; ${ }^{28,29}$ if such a mechanism occurred in adipose tissue, IL-15 could thereby derepress adiponectin secretion.

A number of in vivo studies using both laboratory rodents and human subjects have confirmed the negative association of IL-15 with adiposity, ${ }^{19-22,30,31}$ and have also suggested relationships between IL-15 signaling and insulin sensitivity, ${ }^{25}$ and between IL-15 signaling and oxidative metabolism. ${ }^{32}$ IL-15 upregulation or administration decreases adipose tissue deposition in both wild-type and obese rodents, with no changes in food intake. ${ }^{19,21,22}$ While the in vitro and in vivo effects of IL-15 on adipose tissue are largely consistent, differences between the in vitro and in vivo effects of IL-15 on skeletal muscle are evident. In vivo studies concerning the effects of IL-15 on skeletal muscle mass have yielded conflicting results, including positive, negative, and no effects on muscle mass in different conditions. ${ }^{22,33,34}$

IL-15 signaling can be mediated either through a heterodimeric complex comprising the beta and gamma subunits of the interleukin-2 receptor (IL-2R $\beta$ and IL-2R $\gamma$ ), or through a heterotrimeric complex comprising the IL-15-specific IL-15 receptor-alpha (IL-15R $\alpha$ ) subunit plus IL-2R $\beta$ and IL-2R $\gamma \cdot{ }^{17,29}$ Because constitutive IL-15 overexpression in skeletal muscle does not induce muscle hypertrophy in vivo, ${ }^{22}$ it is possible that high levels or prolonged expression of IL-15 induces downregulation of one or more of the subunits comprising the IL-15 receptor complex in skeletal muscle tissue. Such a mechanism could be responsible for the variable effects of IL-15 on skeletal muscle mass in different experimental regimens.

The present study was undertaken to test three hypotheses: first, IL-15 inhibits diet-induced obesity (DIO) and insulin resistance; second, IL-15 increases circulating HMW adiponectin levels; and third, IL-15 regulates skeletal muscle oxidative metabolism in a manner not manifested by muscle hypertrophy. Implicit in the latter hypothesis is that high levels of IL-15 do not induce muscle IL-15 insensitivity by inducing IL-15 receptor downregulation. Our findings indicate that overexpression of IL-15 reduces total and intra-abdominal fat mass, increases insulin sensitivity, and modulates expression of genes which are involved in oxidative muscle metabolism. However, these effects were not accompanied by elevations in circulating levels of either total or HMW adiponectin, nor induction of skeletal muscle adiponectin mRNA expression. Rather, increased skeletal muscle oxidative capacity may contribute to resistance to DIO and increased insulin sensitivity in IL-15 Tg mice. Inasmuch as IL-15 plays a role in innate immunity, these physiological modulations may function as part of the conversion towards oxidative metabolism which takes place in response to physiological stress. ${ }^{35}$

\section{Materials and methods}

\section{Animal care}

Animal procedures were conducted with the approval of the VA Puget Sound Institutional Animal Care and Use Committee (IACUC), and complied with the ILAR Guide for the Care and Use of Laboratory Animals. Transgenic mice that overexpressed IL-15 from a skeletal musclespecific promoter and, due to manipulation of the transgene signal sequence, exhibited high circulating levels of IL-15 (IL-15 Tg mice) were described previously. ${ }^{22}$ Mice for 
experiments were generated from a specific pathogen-free in-house colony by mating heterozygous IL-15 Tg males with commercially purchased C57BL/6J females (Jackson Laboratories, Bar Harbor, ME) to produce IL-15 Tg mice and closely related control mice on a C57BL/6 background. Mouse pups were genotyped as described previously. ${ }^{22}$ Mice were maintained on an irradiated medium fat/medium energy "breeder" diet ( $4.6 \mathrm{kcal} / \mathrm{g}$ ) by kcal $23 \%$ protein, $22 \%$ fat, and 55\% carbohydrate (PicoLab Mouse Diet 20, Purina Labdiets, St. Louis, MO) until placed on low-fat/low-calorie and high-fat/high-calorie diets (LFD and HFD, respectively) for experimental analyses (described below). For one set of analyses (histological assessment of muscle tissue), 12 weekold mice maintained on the breeder diet were utilized. In all conditions, food and water were provided ad libitum. Mice were maintained on a 12 hour light/12 hour dark cycle at $21 \pm 3^{\circ} \mathrm{C}$, and housed in groups of 2 or 3 in cages consisting of a mixture of control and IL-15 Tg males in each cage. Group housing was utilized to minimize stress as a variable, so assessment of food intake was not possible. Male mice only were used in this study.

For exposure to LFD and HFD, control and IL-15 Tg mice were weaned onto the breeder diet for 1 week, then maintained on the LFD for 3 weeks. At 7 weeks of age, half the cages consisting of a mixture of control and IL-15 Tg mice were switched to the HFD or maintained on the LFD for 20 more weeks. Assays were conducted at 26 to 28 weeks of age. The LFD (DIO Series Diet D12450B, Research Diets Inc., New Brunswick, NJ) consisted by kcal of $20 \%$ protein, $10 \%$ fat, and $70 \%$ carbohydrate $(3.8 \mathrm{kcal} / \mathrm{g})$. The HFD (DIO Series Diet D12492, Research Diets) consisted by kcal of $20 \%$ protein, $60 \%$ fat, and $20 \%$ carbohydrate $(5.2 \mathrm{kcal} / \mathrm{g})$. Blood samples for cytokine and hormone assays were obtained after 19 weeks of LFD or HFD feeding regimens in fasted (6 hours), isoflurane-anesthetized mice by sampling from the submandibular vein. Blood was not obtained at the commencement of the feeding regimens because insufficient volume was obtainable for cytokine assays due to the small size of the mice at that point.

\section{Body composition}

Body composition was evaluated on conscious mice following 18 weeks of LFD or HFD feeding regimens by quantitative magnetic resonance (QMR) spectroscopy using an EchoMRI-100 mouse body composition analyzer (Echo Medical Systems, Houston, TX) and EchoMRI software. Lean body mass and total body fat mass were quantified based on the averages of triplicate measures for each animal, with a $\mathrm{CV}$ of $<2 \%$ for fat mass and $<4 \%$ for lean mass. ${ }^{36}$ Mice were too small ( $<20 \mathrm{~g}$ at 7 weeks of age) for body composition analysis at the commencement of the feeding regimen.

\section{Blood glucose determination and insulin tolerance tests (ITTs)}

Following the 20 week LFD or HFD feeding regimens, food was withdrawn in the morning 6 hours prior to blood glucose determination or ITTs to normalize baseline blood glucose levels. ${ }^{37}$ Baseline blood glucose levels in conscious mice were determined using a subset of mice subjected to the LFD and HFD feeding regimens, but subsequent ITTs were confounded in conscious mice due to handling stress from repeated blood sampling. Therefore, for ITTs in a separate set of mice, animals were anesthetized with pentobarbital $(80 \mathrm{mg} / \mathrm{kg}$, intraperitoneal [IP]) and body temperature was maintained using a water-based heating pad for 40 minutes to allow clearance of the acute effects of pentobarbital on hepatic glucose release. ${ }^{38}$ This anesthetic nevertheless results in elevated blood glucose levels. ${ }^{39}$ After 40 minutes, baseline blood glucose was determined by sampling from the tail tip, then human insulin was administered IP at $1 \mathrm{U} / \mathrm{kg}$ body weight. Blood glucose was determined at baseline and at 15, 30, 45, and 60 minutes after IP insulin using a research-grade AlphaTRAK glucometer (Abbott Animal Health, Abbott Park, IL). Mice underwent euthanatization by an overdose of pentobarbital without regaining consciousness. Following euthanatization, extensor digitorum longus (EDL) and soleus muscles, as well as the retroperitoneal fat pad, were carefully dissected and weighed. Muscles were then processed for mRNA analyses as described below.

\section{Gene expression assays}

Tissue samples were submerged in RNALATER RNA Stabilization Reagent (Qiagen, Valencia, CA) and stored frozen at $-20^{\circ} \mathrm{C}$. RNA was isolated from the EDL and soleus muscles by homogenization in Trizol (Life Technologies, Grand Island, NY) followed by isopropanol precipitation. Resuspended RNA was treated with DNase and further purified using RNeasy spin columns (Qiagen). RNA (1.5 $\mu \mathrm{g}$ ) was reverse transcribed into cDNA using an $\mathrm{RT}^{2}$ First Stand Kit (SABiosciences, Frederick, MD) which contains an additional genomic DNA removal buffer. Before use, the quality of reverse transcription reactions was assessed using a housekeeping gene, hypoxanthine phosphoribosyltransferase 
1 (HPRT1). Real-time PCR was utilized to assess mRNA expression of various genes, using primers supplied by SABiosciences. Diluted RT reactions were combined with RT $^{2}$ Real-Time SYBR Green/Fluorescein PCR Master Mix (SABiosciences) and distributed equally among wells of PCR plates. Plates were cycled as specified by SABiosciences for a BioRad iCycler (BioRad, Hercules, CA), with the threshold value for all plates in a comparison set to an identical level. Data were analyzed by the $\Delta \Delta \mathrm{C}_{\mathrm{T}}$ method in which the $\mathrm{C}_{\mathrm{T}}$ for each sample was normalized to expression of HPRT1 $\left(\Delta \mathrm{C}_{\mathrm{T}}\right)$; relative mRNA expression of each gene in each experimental group is presented as fold change compared with a baseline group within the same set of samples, generally control mice on LFD.

\section{Assays of circulating cytokines and hormones}

Blood was allowed to clot at RT for 45 minutes in separator tubes (Micro Tubes with Gel; Iris International, Westwood, MA), centrifuged at 14,000 rpm for 2 minutes. Serum was removed and stored frozen at $-20^{\circ} \mathrm{C}$ in aliquots. Serum IL-15, IL-6, TNF- $\alpha$, and interleukin- $1 \beta$ (IL-1 $\beta$ ) levels were assessed using BioRad kits specific for mouse analytes in a BioPlex Protein Array instrument (BioRad). Sensitivity of the IL-15 assay was $6.6 \mathrm{pg} / \mathrm{mL}$ with intra-assay CV $6 \%$; sensitivity of the IL-6 assay was $0.2 \mathrm{pg} / \mathrm{mL}$ with intra-assay $\mathrm{CV} 3 \%$; sensitivity of the TNF- $\alpha$ assay was $1.4 \mathrm{pg} / \mathrm{mL}$ with intra-assay CV 3\%; sensitivity of the IL- $1 \beta$ assay was $10.36 \mathrm{pg} / \mathrm{mL}$ with intra-assay CV 4\%. Total and HMW adiponectin levels were determined using a mouse adiponectin total/HMW ELISA kit (ALPCO, Salem, NH) with sensitivity $0.032 \mathrm{ng} / \mathrm{mL}$ and intra-assay $\mathrm{CV} 2 \%$ to $4 \%$ for each form. Insulin was determined with a mouse insulin ELISA kit (ALPCO), with sensitivity $0.121 \mathrm{ng} / \mathrm{mL}$ and intra-assay CV 3.7\%. Leptin levels were assessed with a Milliplex mouse adipocyte (leptin analyte) immunoassay (Millipore Corporation, Billerica, MA), with sensitivity $0.5 \mathrm{ng} / \mathrm{mL}$ and intra-assay $\mathrm{CV} 1.1 \%$ to $1.8 \%$.

\section{Muscle histochemistry}

EDL (predominately fast/glycolytic) and soleus (predominately slow/oxidative) muscles from 12 week-old male control and IL-15 Tg mice maintained on the breeder diet were utilized for histochemical determination of succinic dehydrogenase (SDH) activity, a measure of mitochondrial content. Frozen sections $(10 \mu \mathrm{m})$ were cut from the midbelly, processed for SDH activity as described previously, ${ }^{40}$ and post-fixed in $4 \%$ paraformaldehyde for 5 minutes. The numbers of SDH- (light) and SDH+ (dark) fibers in each muscle were quantified; staining intensity was not quantified. Mean fiber diameters were determined from alternate sections stained with hematoxylin and eosin.

\section{Statistical procedures}

Data represent 3 to 6 mice per group and are expressed as mean \pm SEM. Statistical analyses were performed using SigmaStat 3.0 software (Systat Software Inc., San Jose, CA). For most parameters, the significance of main genotype $\times$ diet effects, and possible interactions of these factors, were analyzed by 2-way analysis of variance (ANOVA). Posthoc pairwise multiple comparisons were performed using Bonferroni $t$-tests. When considering time effects on weight and insulin sensitivity, repeated measure procedures were used. Percent SDH+ fibers was compared by $t$ tests. Significant differences $(P<0.05)$ are noted in the table and figures.

\section{Results \\ Body composition in response to low- and high-fat feeding}

No significant differences in initial body weight among groups were observed (Table 1). However, after high-fat feeding, control mice weighed significantly more than IL-15 Tg mice (Table 1 and Figure 1A). Compared with controls, total body fat was significantly lower in IL-15 Tg mice exposed to the HFD (Figure 1B). The weight of the retroperitoneal fat pad, a measure of intra-abdominal fat mass, was significantly lower in IL-15 Tg mice after both low and high-fat feeding regimens (Figure 1C). Exposure to the HFD significantly increased lean body mass in both control and IL-15 Tg mice; however, lean body mass did not differ between control and IL-15 Tg mice after either diet regimen (Figure 1D). Although there was no effect of genotype on overall lean mass, a significant effect of genotype on mass of the predominately slow, oxidative soleus muscle was observed, with soleus muscles from IL-15 Tg mice slightly heavier than those of controls (Figure 1E). No effect of genotype was observed for mass of the predominately fast EDL muscle; however, a significant effect of diet was observed (Figure 1F).

\section{Serum cytokines}

Serum leptin levels were significantly lower in IL-15 Tg mice compared with controls after exposure to both LFD and HFD (Table 1), reflecting the different levels of adiposity in the two genotypes. There was also a significant effect of diet on 
Table I Body weight and serum cytokines in control and IL-I5 Tg mice

\begin{tabular}{|c|c|c|c|c|c|c|c|}
\hline \multirow[t]{2}{*}{ Parameter } & \multirow{2}{*}{$\begin{array}{l}\text { Control } \\
\text { LFD }^{2}\end{array}$} & \multirow{2}{*}{$\begin{array}{l}\text { IL-I } 5 \text { Tg } \\
\text { LFD }\end{array}$} & \multirow{2}{*}{$\begin{array}{l}\text { Control } \\
\text { HFD }\end{array}$} & \multirow{2}{*}{$\begin{array}{l}\text { IL-I } 5 \text { Tg } \\
\text { HFD }\end{array}$} & \multicolumn{2}{|c|}{ Genotype } & \multirow{2}{*}{$\frac{\text { Diet interaction }}{P \text { value }^{\prime}}$} \\
\hline & & & & & $P$ value ${ }^{\prime}$ & P value' & \\
\hline IBW (g) & $19.7 \pm 0.4$ & $19.9 \pm 0.3$ & $20.0 \pm 0.4$ & $19.6 \pm 0.3$ & ns & ns & ns \\
\hline $\mathrm{FBW}(\mathrm{g})$ & $32.3 \pm 1.4^{a}$ & $32.7 \pm 1.4^{\mathrm{a}}$ & $49.4+1.6^{b}$ & $42.2 \pm 1.4^{c}$ & $<0.05$ & $<0.001$ & $<0.05$ \\
\hline Leptin (ng/mL) & $10.4 \pm 2.5$ & $3.6 \pm 2.5$ & $41.1 \pm 2.9$ & $15.5 \pm 2.3$ & $<0.001$ & $<0.001$ & $<0.01$ \\
\hline IL-I5 (ng/mL) & $0.1 \pm 0.0 \mathrm{I}^{\mathrm{a}}$ & $12.2 \pm 0.3^{b}$ & $0.1 \pm 0.0 \mathrm{I}^{\mathrm{a}}$ & $12.5 \pm 0.3^{b}$ & $<0.00$ I & ns & ns \\
\hline IL-6 (pg/mL) & $1.1 \pm 0.2$ & $1.7 \pm 0.5$ & $1.7 \pm 0.5$ & $3.1 \pm 1.0$ & ns & ns & ns \\
\hline TNF- $\alpha(p g / m L)$ & OOR & OOR & OOR & OOR & na & na & na \\
\hline IL-I $\beta$ (pg/mL) & $77.3 \pm 18.7$ & $51.6 \pm 18.7$ & $68.9 \pm 21.6$ & $50.0 \pm 16.8$ & ns & ns & ns \\
\hline
\end{tabular}

Notes: Cytokines were assessed following 19 weeks of high- or low-fat feeding regimens. Values are reported as mean \pm SEM; 'determined by 2 -way ANOVA. Differences among groups in each row determined by post-hoc analyses are designated by superscripted letters; values with different superscripts are different at $P<0.05$; ns, not significant; na, not applicable.

Abbreviations: IBW, initial body weight; FBW, final body weight at 20 weeks; IL-I 5, interleukin-I5; IL-6, interleukin-6; TNF- $\alpha$, tumor necrosis factor-alpha; IL-I $\beta$, interleukinIbeta; HFD, high-fat diet; LFD, low-fat diet; OOR, out of range of assay.

circulating leptin levels for both genotypes, and a significant diet $\times$ genotype interaction (Table 1 ). As expected, ${ }^{22}$ serum IL-15 levels in IL-15 Tg mice were significantly higher than those of controls (Table 1). However, there was no effect of diet on circulating IL-15 levels in either genotype (Table 1). Serum levels of three other cytokines involved in body composition and insulin sensitivity, ${ }^{8,9}$ interleukin- 6 (IL-6), TNF- $\alpha$, and IL-1 $\beta$, were also measured. TNF- $\alpha$ was undetectable in all serum samples, and no significant effect of either genotype or diet on serum IL- 6 or IL- $1 \beta$ levels was observed (Table 1).

\section{Insulin sensitivity and related parameters}

While high-fat feeding increased circulating insulin levels in both control and IL-15 Tg mice, there was no effect of genotype (Figure 2A). Significant effects of both genotype and diet were observed for fasting blood glucose levels in conscious mice (Figure 2B). IL-15 Tg mice were more sensitive to insulin than controls after both LFD and HFD feeding regimens (Figure 2C and D). An effect of diet was not observed, possibly due to the use of pentobarbital anesthesia, which also elevated baseline blood glucose levels in the ITTs. ${ }^{39}$ However, while exposure to the HFD decreased circulating levels of both total and HMW adiponectin, no effect of genotype was detected for either form (Figure 3A and B). Therefore, higher circulating adiponectin levels were not responsible for the increased insulin sensitivity exhibited by IL-15 Tg mice.

Skeletal muscle adiponectin mRNA expression has been reported to correlate with elevated intramyocellular lipid levels. ${ }^{13}$ While control mice upregulated adiponectin mRNA expression in response to the HFD in both the slow/ oxidative soleus and fast/glycolytic EDL muscles, no such regulation was observed in these muscles in IL-15 Tg mice (Figure $3 \mathrm{C}$ and $\mathrm{D}$ ).

\section{Markers of oxidative metabolism in soleus and EDL muscles}

Markers of oxidative metabolism were examined at the mRNA level in the predominately slow soleus muscle and predominately fast EDL muscle following the diet regimens. These assays indicated significant upregulation of mRNA coding for the slow isoform of troponin I (TnnI 1) in IL-15 Tg soleus and EDL muscles compared with controls (Figure 4A and B). The 10-fold difference in expression of TnnI 1 in the EDL was much greater than that of the soleus (1.5- to 2-fold); however, overall abundance of TnnI 1 in the soleus was about 300 times higher than in EDL (not shown). Significant downregulation of mRNA coding for the fast isoform of troponin I (TnnI 2) was also observed in IL-15 Tg soleus muscles (Figure 4C), but not in the EDL (not shown). No effects of diet on these parameters were detected. These findings suggest that constitutive IL-15 overexpression induced a shift in muscle fiber gene expression towards a more oxidative muscle phenotype. However, in an additional study performed using mice maintained on medium-fat "breeder" diets, no differences in the percentage of SHD+ muscle fibers (a measure of mitochondrial density) in the EDL of control and IL-15 Tg mice were observed, and all fibers in the soleus muscle of both control and IL-15 Tg mice were SDH+ (Figure 4D). Additionally, no significant differences in mean fiber diameter were observed between control and IL-15 Tg mice in either muscle (data not shown).

We also examined expression of several factors involved in mitochondrial biogenesis, oxidative metabolism, and muscle fiber-type determination, including peroxisome proliferator-activated receptors (PPAR $\alpha, \delta$, and $\gamma$ ), ${ }^{41}$ the mammalian sirtuin family members (SIRT1-7), ${ }^{35,42-44}$ downstream effectors of sirtuin action (PPAR $\gamma$ coactivators; PGC-1 $\alpha$ and $-1 \beta),{ }^{44-46}$ and the mitochondrial uncoupling 


\section{A Body weight}

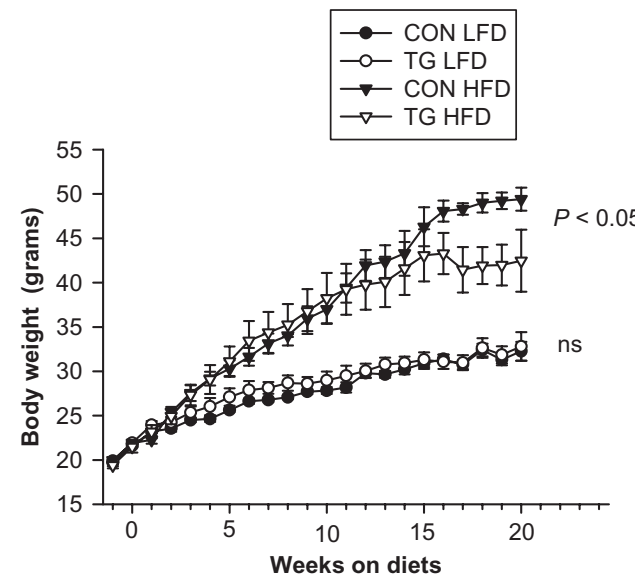

C Intra-abdominal fat mass

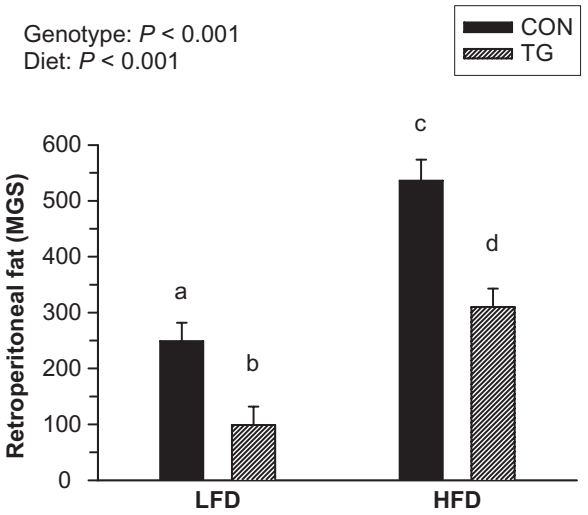

E Soleus muscle mass

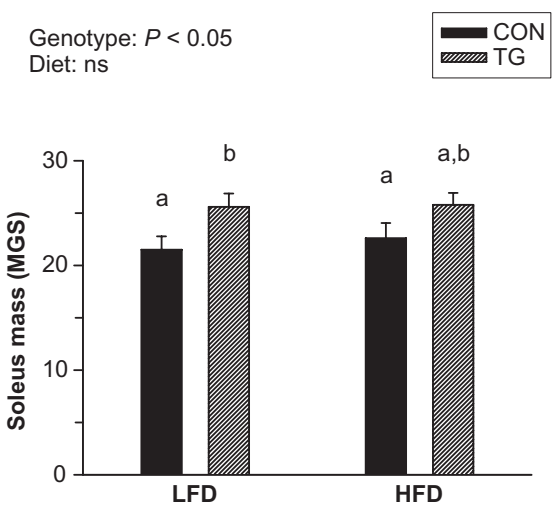

\section{B Total body fat}

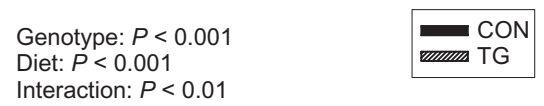

Interaction: $P<0.01$

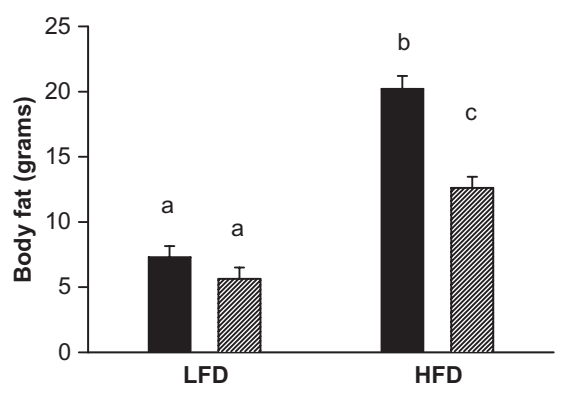

D Lean body mass
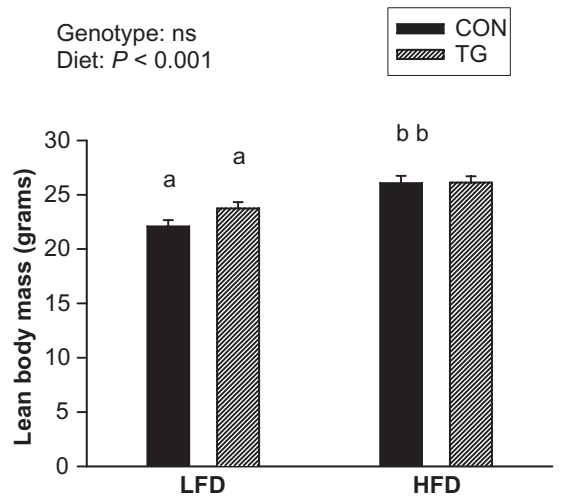

F EDL muscle mass
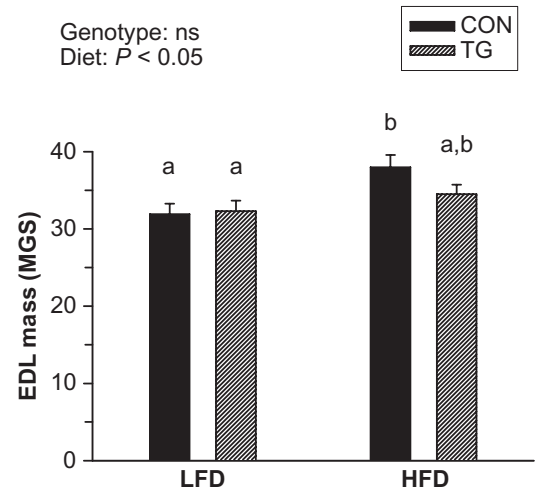

Figure I Body weight changes and final body composition of control (CON) and IL-15 Tg (TG) mice following 20 weeks of low-fat diet (LFD) or high-fat diet (HFD) regimens. A) Body weight changes over 21 weeks of diet regimens, starting I week before diet change. B) Total body fat (g). C) Retroperitoneal fat pad mass (mg), a measure of intraabdominal fat. D) Lean body mass (g). E) Soleus muscle mass (mg). F) Extensor digitorum longus (EDL) mass (mg). Symbols and bars represent mean \pm SEM. Significance of main genotype $\times$ diet effects was determined by repeat measure ANOVA (A) or 2-way ANOVA (B-F); interactions are noted only when significant $(P<0.05)$. In B-F, bars with different superscripts are significantly different $(P<0.05)$ by post-hoc analyses.

proteins (UCP1-3). ${ }^{47,48}$ Soleus, but not EDL, muscles in IL-15 Tg mice exhibited a small, diet-dependent upregulation of SIRT1 mRNA (Figure 5A), and diet-independent downregulation of SIRT3 and SIRT4 mRNA expression (Figure 5B and C). Additionally, UCP2 was significantly upregulated in EDL (but not soleus) muscles of IL-15 Tg mice compared with controls in a diet-independent fashion (Figure 5D). No effects of genotype on expression of the PPARs, PGCs, other sirtuins, or other UCPs were detected in soleus and EDL muscles (not shown). 


\section{A Fasting insulin}

Genotype: ns Diet: $P<0.001$
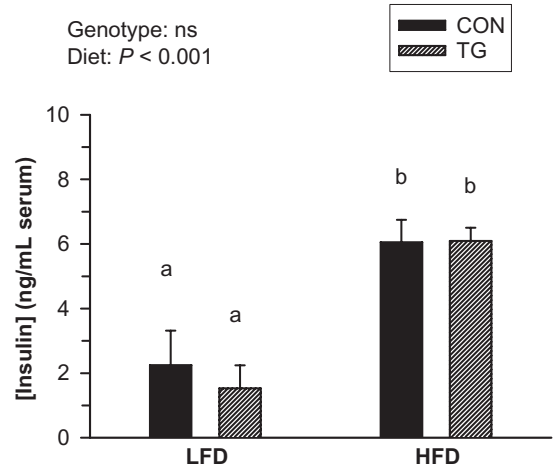

C Insulin tolerance test

Genotype: $P \leq 0.01$ Diet: ns

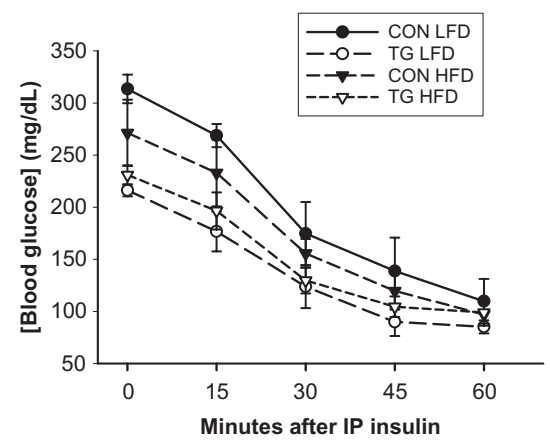

B Fasting blood glucose

Genotype: $P<0.05$

Diet: $P<0.05$
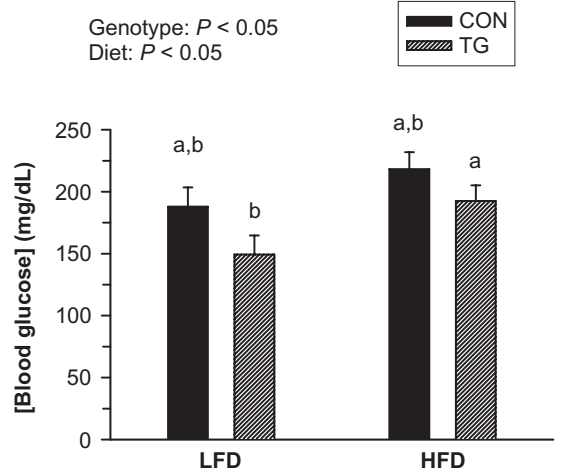

D Insulin tolerance - auc

Genotype: $\mathrm{P} \leq 0.05$

Diet: ns
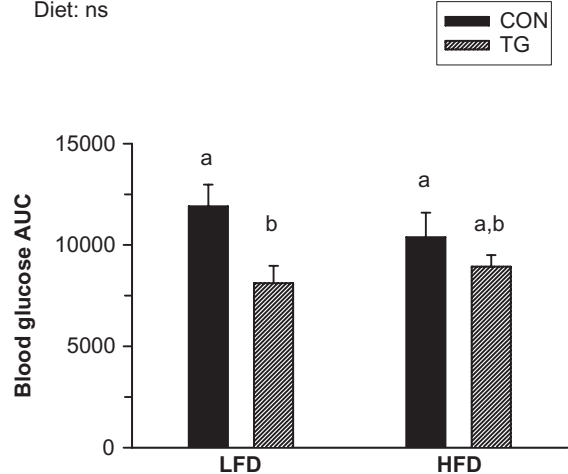

Figure 2 Insulin sensitivity and related parameters in control (CON) and IL-I5 Tg (TG) mice following 19 to 20 weeks of low-fat diet (LFD) or high-fat diet (HFD) regimens. A) Fasting insulin ( $\mathrm{ng} / \mathrm{mL}$ serum) at 19 weeks. B) Fasting blood glucose ( $\mathrm{mg} / \mathrm{dl})$ in conscious mice at 20 weeks. C) Insulin tolerance tests at 20 weeks in pentobarbitalanesthetized mice. Mice received IP insulin at I U/kg body weight and blood glucose was determined at I5 min intervals. Data points represent means of 4 mice per group \pm SEM. Data were analyzed by 2-way repeat measure ANOVA. D) Insulin tolerance area under the curve (AUC) determined from blood glucose data shown in panel C. For panels A, B, and D, bars represent mean \pm SEM. Significance of main genotype $\times$ diet effects was determined by 2 -way ANOVA; no significant interactions were observed. Bars with different superscripts are significantly different $(P<0.05)$ by post-hoc analyses.

\section{Expression of IL-I5 receptor subunits in skeletal muscle tissue}

Because we observed minimal differences in skeletal muscle mass between control and IL-15 Tg mice, we explored the possibility that IL-15 receptor subunits were downregulated in skeletal muscle tissue of IL-15 Tg mice. However, no effects of genotype or diet were observed for IL-15R $\alpha$ mRNA expression by either the soleus or EDL muscle (Figure 6A and B). IL-2R $\gamma$ expression was significantly higher in EDL muscles of IL-15 Tg mice compared with controls, but was similar in soleus muscles of control and IL-15 Tg mice (Figure 6C and D). Additionally, expression of the relatively rare transcript for IL-2R $\beta$ was greatly upregulated in both soleus and EDL muscles of IL-15 Tg mice compared with controls (Figure 6E and F).

\section{Discussion}

This study confirmed previous findings indicating that overexpression of IL-15 in IL-15 Tg mice reduces fat mass and promotes resistance to DIO. ${ }^{22}$ We also showed that IL-15 reduced intra-abdominal fat mass and circulating leptin levels, increased insulin sensitivity, and induced a pattern of skeletal muscle gene expression consistent with an increase in oxidative metabolism. We found no evidence for IL-15 receptor downregulation in skeletal muscles of IL-15 Tg mice at the mRNA level.

Our observations are consistent with previous studies indicating that differences in body composition between control and IL-15 Tg mice are largely due to decreased deposition of white adipose tissue by the transgenic mice. ${ }^{22}$ In the present study, mice were group-housed in order to minimize stress as a variable; therefore, food intake could not be assessed. However, a very similar study utilizing single housing of control and IL-15 Tg mice revealed no differences in food intake between these genotypes on either LFD or HFD, while differences in body composition were similar to those observed in the present study. ${ }^{22}$ Other studies, using shorterterm administration of IL-15 via injection of recombinant 


\section{A Serum total adiponectin}

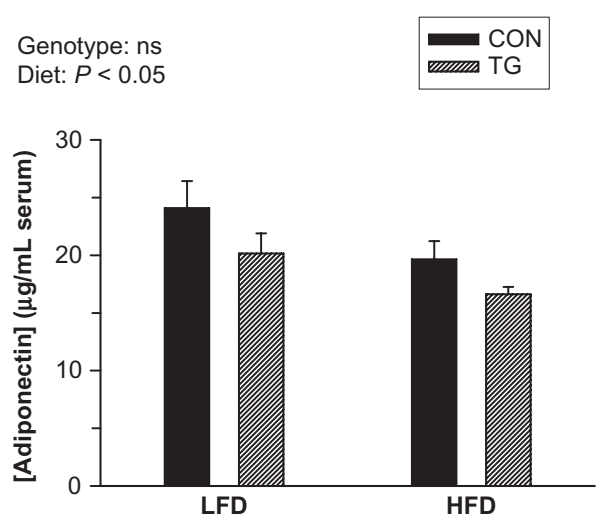

C Soleus adiponectin mRNA

Genotype: ns Diet: $P<0.05$

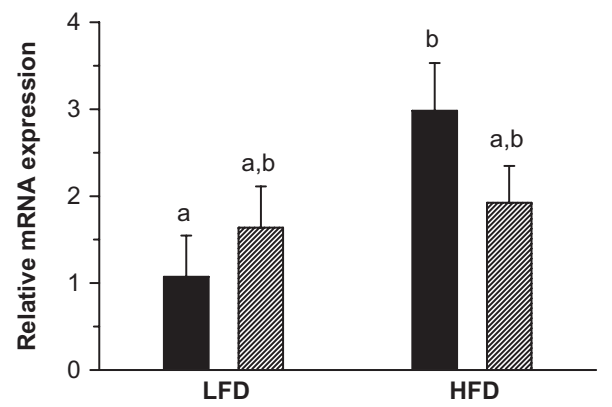

\section{B Serum HMW adiponectin}

Genotype: ns

Diet: $P<0.01$
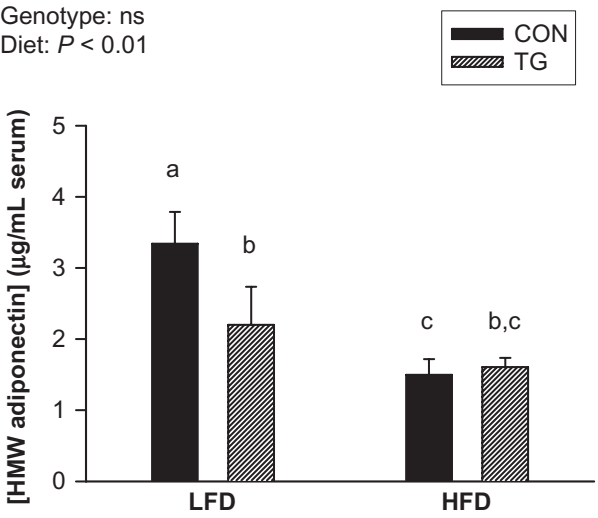

D EDL adiponectin mRNA

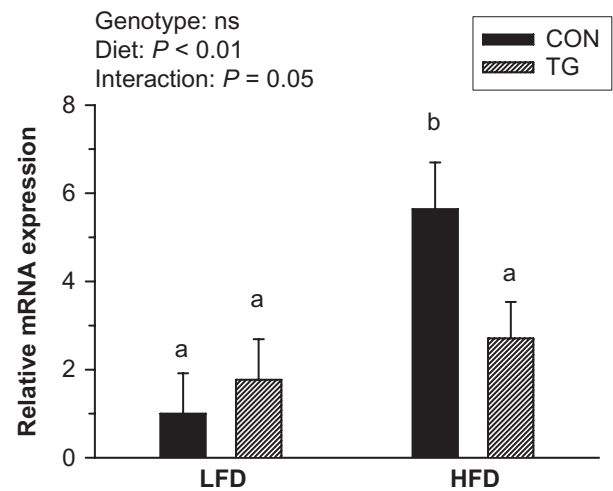

Figure 3 Circulating adiponectin levels (19 weeks) and muscle adiponectin mRNA expression (20 weeks) following low-fat diet (LFD) or high-fat diet (HFD) regimens in control (CON) and IL-I5 Tg (TG) mice. A) Serum total adiponectin ( $\mu \mathrm{g} / \mathrm{mL})$. B) Serum high-molecular-weight (HMW) adiponectin ( $\mu g / \mathrm{mL})$. C) Soleus muscle adiponectin mRNA expression (fold difference relative to LFD CON value). D) Extensor digitorum longus (EDL) muscle adiponectin mRNA expression (fold difference relative to LFD CON value). Bars represent mean \pm SEM. Significance of main genotype $\times$ diet effects was determined by 2 -way ANOVA; interactions are noted only when significant $(P<0.05)$. Bars with different superscripts are significantly different $(P<0.05)$ by post-hoc analyses.

protein or introduction of adenoviral IL-15 expression vectors, have likewise indicated that IL-15 administration reduces fat mass in both lean and obese rodent models. ${ }^{20-22,31}$ Moreover, mice with a targeted deletion of IL-15 exhibited greatly increased fat mass. ${ }^{21}$ Food intake was assessed in each of these studies, and no effects of IL-15 deletion or addition on food intake were observed..$^{20-22,31}$ Taken together, these observations suggest that the action of IL-15 on body composition may involve modulations of energy metabolism rather than changes in energy intake.

We observed that high-fat feeding increased circulating insulin levels, but there was no effect of IL-15 overexpression on this parameter. However, other lines of evidence indicated that IL-15 overexpression increased insulin sensitivity in our mouse model. In conscious mice, blood glucose levels were significantly lower in IL-15 Tg mice than controls after exposure to both the LFD and HFD; a significant effect of diet on blood glucose was also observed. ITTs, performed under pentobarbital anesthesia, additionally indicated that IL-15 Tg mice were more insulin-sensitive than controls. However, no effect of diet on this parameter was observed, and baseline blood glucose levels under these conditions were elevated due to the use of anesthetic. ${ }^{39}$ This was an unavoidable technical problem with this procedure, as we found that ITTs performed with conscious mice were confounded by handling stress. The ITT test predominately reflects the stimulation of glucose uptake by skeletal muscle tissue. ${ }^{39}$ Previous studies by other groups have reported that a single IV dose of recombinant IL-15 increased glucose transport into rat skeletal muscles, and had the same effect on isolated muscle preparations and cultured $\mathrm{C} 2 \mathrm{C} 12$ muscle cultures. ${ }^{23}$ These observations support our interpretation that IL-15 increases insulin sensitivity and glucose uptake by skeletal muscle tissue.

Our findings using transgenic mice correspond to observations on human subjects which link IL-15 with adiposity 


\section{A Soleus troponin I 1 (slow) mRNA}

Genotype: $P<0.05$

Diet: ns

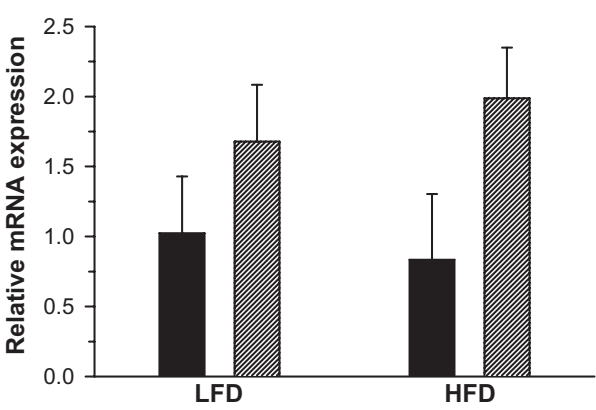

\section{Soleus troponin I 2 (fast) mRNA}

Genotype: $\mathrm{P}<0.01$

Diet: ns
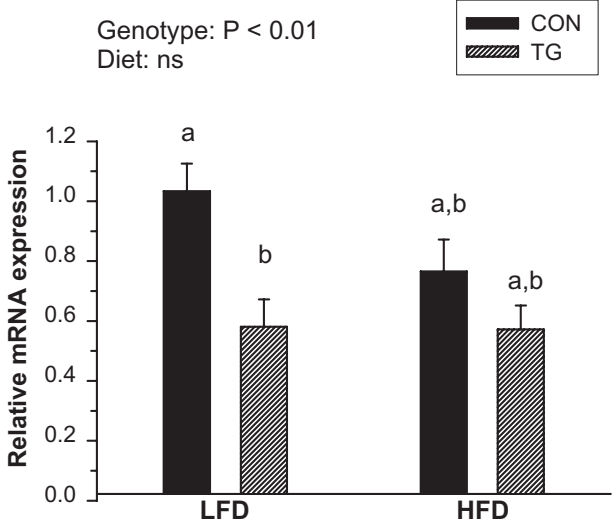

\section{B EDL troponin I 1 (slow) mRNA}

Genotype: $\mathrm{P}<0.001$

Diet: ns
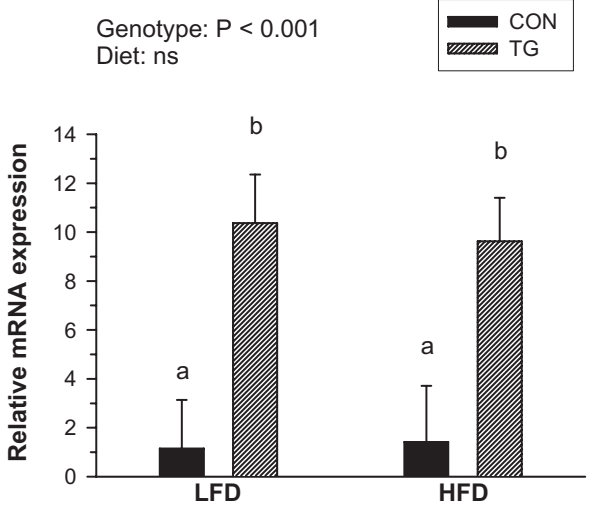

D SDH staining
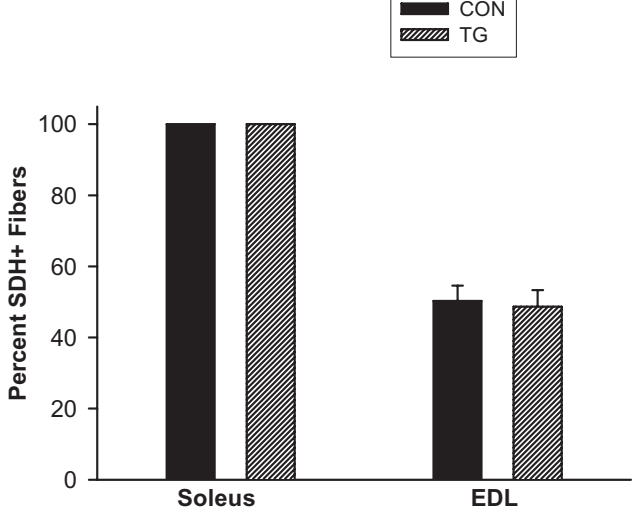

Figure 4 Markers of oxidative skeletal muscle phenotype in control (CON) and IL-I5 Tg (TG) mice. A) Soleus troponin I I (slow) mRNA expression. B) Extensor digitorum longus (EDL) troponin I I (slow) mRNA expression. C) Soleus troponin I 2 (fast) mRNA expression. D) Succinic dehydrogenase (SDH) staining (expressed as percent SDH+ fibers) in soleus and EDL. For panels A-C, samples were assessed following 20 weeks of low-fat diet (LFD) or high-fat diet (HFD) regimens. Relative mRNA expression in each panel represents fold difference relative to LFD CON value; troponin I I expression in soleus was approximately 300 times higher than in EDL. Significance of main genotype $\times$ diet effects was determined by 2 -way ANOVA; no significant interactions were detected. Bars with different superscripts are significantly different $(P<0.05)$ by post-hoc analyses. For panel D, data were assessed in 12 week-old mice maintained on a medium-fat (breeder) diet, and differences between CON and TG were assessed for each muscle using $t$ tests. Bars in all panels represent mean \pm SEM.

and insulin sensitivity. Circulating IL-15 levels correlate negatively with obesity and abdominal fat in humans. ${ }^{20,21}$ Additionally, two studies have demonstrated correlations between single-nucleotide polymorphisms in human IL15 and IL15RA (the genes which direct expression of IL-15 and the IL-15R $\alpha$, respectively) and adiposity and/or markers of the metabolic syndrome. ${ }^{25,49}$ A recent genome-wide survey of human copy number variations that correlated with obesity revealed a large $(2.1 \mathrm{Mb})$ deletion of a region including both IL15 and UCP1 was associated with moderate obesity. ${ }^{30}$

On the basis of experiments using cultured adipocytes, we hypothesized that the effects of IL-15 on adiposity and insulin sensitivity would be accompanied by elevations in circulating total and/or HMW adiponectin. However, while exposure to high-fat feeding significantly decreased levels of both forms of adiponectin in serum, there was no effect of genotype on these parameters. It is unclear how much skeletal muscle, as opposed to adipose tissue, contributes to circulating adiponectin levels. ${ }^{8,14}$ Krause et al $^{13}$ reported that skeletal muscle tissue upregulates adiponectin mRNA in response to high-fat feeding, and that expression of adiponectin mRNA in muscle is correlated with elevated intramyocellular lipid content. In our study, control, but not IL-15 Tg mice on the HFD exhibited significant upregulation of adiponectin mRNA in both soleus and EDL muscles, suggesting that IL-15 Tg mice may not accumulate as much intramuscular lipid as controls following high-fat feeding. Neither intramuscular lipid nor lipid oxidation were measured directly in this study. Almendro et al ${ }^{32}$ reported significantly reduced fat content in the mixed gastrocnemius muscle of rats that received daily injections of recombinant IL-15 for 1 week. Moreover, the same study reported IL-15 treatment 


\section{A Soleus SIRT1 mRNA}

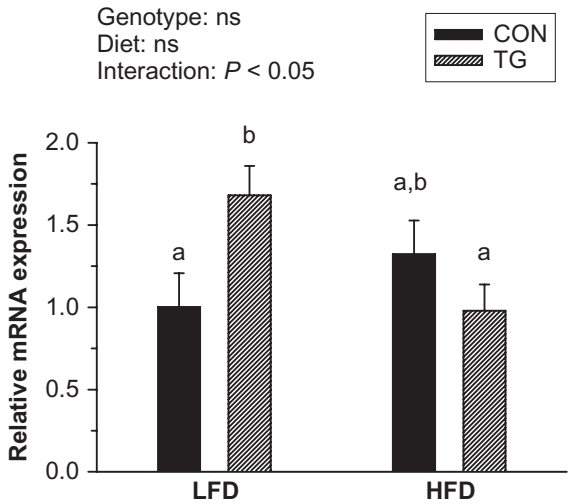

C Soleus SIRT4 mRNA

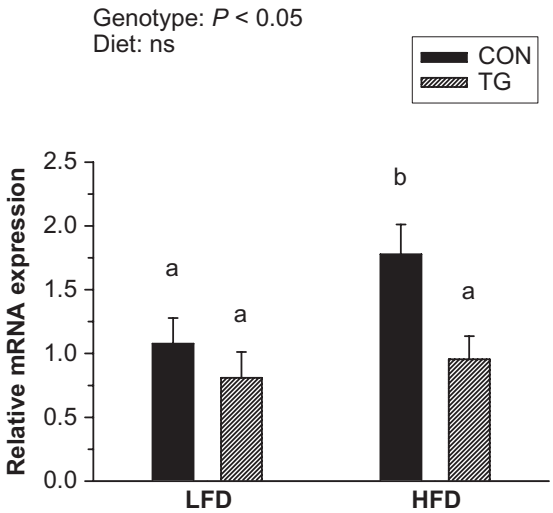

B Soleus SIRT3 mRNA

Genotype: $P<0.01$ Diet: ns
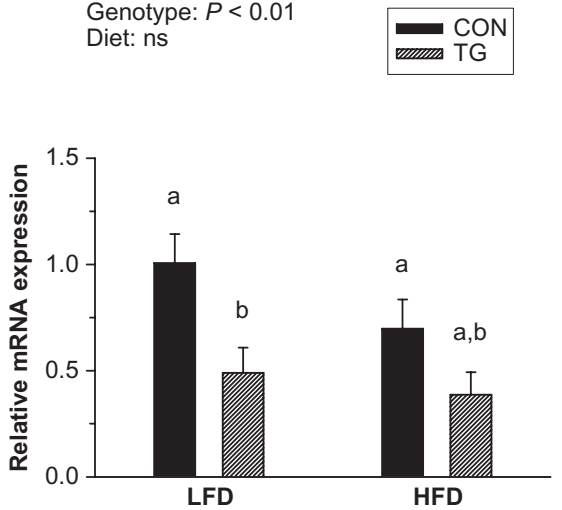

D EDL UCP2 mRNA

Genotype: $P<0.05$

Diet: ns
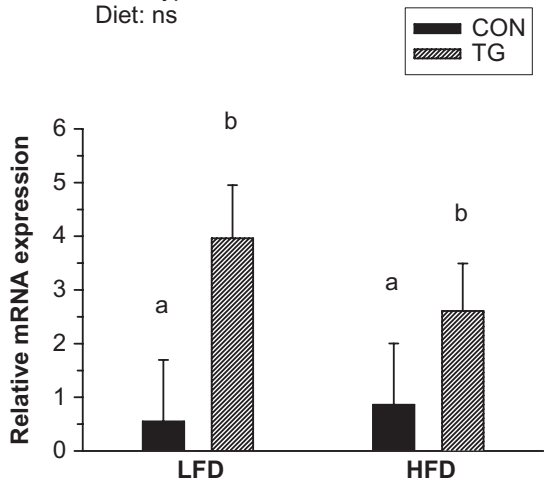

Figure 5 Skeletal muscle mRNA expression of metabolic effectors following 20 weeks of low-fat diet (LFD) or high-fat diet (HFD) regimens in control (CON) and IL-I5 $\mathrm{Tg}(\mathrm{TG})$ mice. Relative mRNA expression in each panel represents fold difference relative to LFD CON value. A) Soleus SIRTI mRNA. B) Soleus SIRT3 mRNA. C) Soleus SIRT4 mRNA. D) Extensor digitorum longus (EDL) uncoupling protein 2 (UCP2) mRNA. Bars represent mean \pm SEM. Significance of main genotype $\times$ diet effects was determined by 2 -way ANOVA; interactions are noted only when significant $(P<0.05)$. Bars with different superscripts are significantly different $(P<0.05)$ by post-hoc analyses.

decreased incorporation of radiolabeled lipid into adipose tissue, and increased fatty acid oxidation in isolated skeletal muscle preparations. ${ }^{32}$ Therefore, our findings and those of others suggest that IL-15 may increase lipid oxidation in skeletal muscle tissue.

In agreement with this interpretation, we observed differences in skeletal muscle gene expression patterns which were indicative of a shift towards increased oxidative capacity. Compared with controls, muscle tissue in IL-15 Tg mice exhibited shifts in expression of TnnI isoforms towards a more oxidative pattern. We additionally observed a dietdependent modulation of muscle SIRT1 expression, decreased expression of SIRT3 and 4, and upregulation of UCP2. Both SIRT1 and UCP2 have been implicated in promotion of lipid oxidation, ${ }^{35,48}$ while SIRT4 inhibits fatty acid oxidation. ${ }^{42}$ Therefore, the observed modulation of TnnI isoform, sirtuin, and UCP2 mRNA expression is consistent with an increase in skeletal muscle oxidative capacity in IL-15 Tg mice.
SIRT1 can activate PGC-1 $\alpha$, which in turn co-activates PPAR $\gamma$ to stimulate fatty acid oxidation. ${ }^{43}$ PGC- $1 \alpha$ can also induce UCP2 mRNA expression in cultured muscle cells in a PPAR $\gamma$-independent manner. ${ }^{50}$ However, no effects of genotype on expression of the PPARs, PGCs, other sirtuins, or other UCPs were detected in soleus and EDL muscles (not shown). These observations do not preclude the possibility of alterations in activation of these molecules in IL-15 Tg mice, which were not detectable by analyses of mRNA expression. Our findings suggest that increased skeletal muscle oxidative capacity may contribute to resistance to DIO and increased insulin sensitivity in IL-15 Tg mice. This interpretation requires further investigation, particularly at the protein level. Examination of the contribution of other tissues involved in energy balance (liver, adipose tissue) is also warranted.

In contrast to our findings, one report found increased expression of PPAR $\delta$ mRNA in skeletal muscle tissue of rats that were administered recombinant IL-15 for 1 week. ${ }^{32}$ 


\section{A Soleus IL-15R $\alpha$ mRNA}

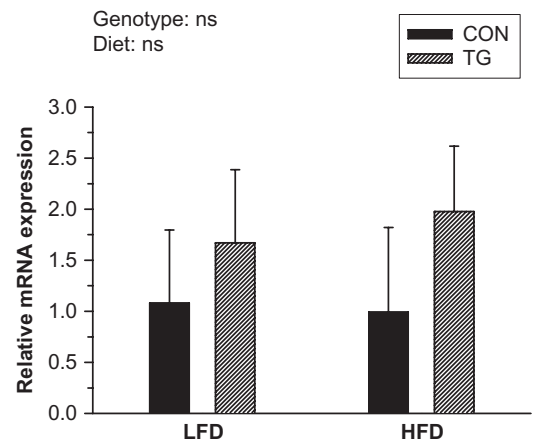

C Soleus IL-2R $\gamma$ mRNA

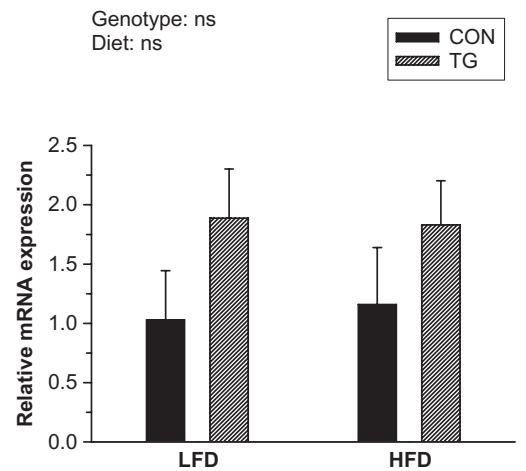

\section{E Soleus IL-2Rß mRNA}

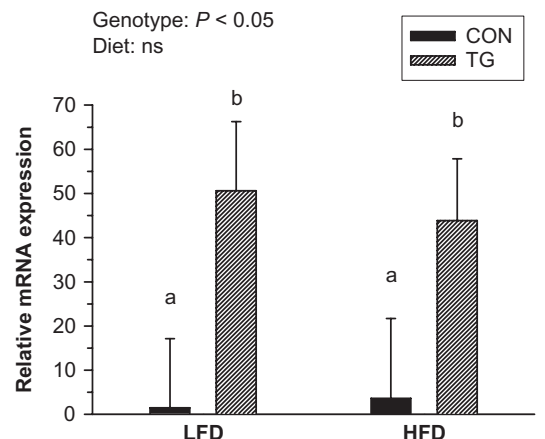

B EDL IL-15R $\alpha$ mRNA

Genotype: ns Diet: ns
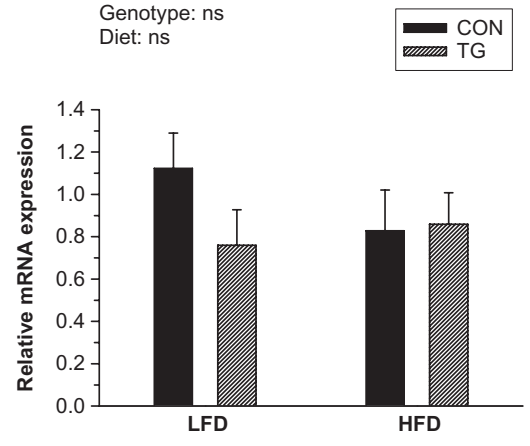

D EDL IL-2R $\gamma$ mRNA

$$
\text { Genotype: } P \leq 0.001
$$

Diet: ns
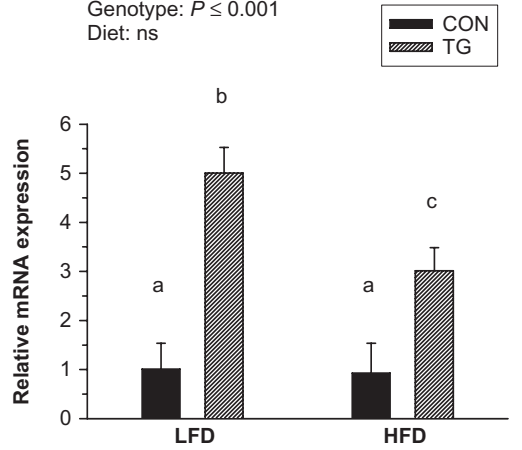

F EDL IL-2R $\beta$ mRNA

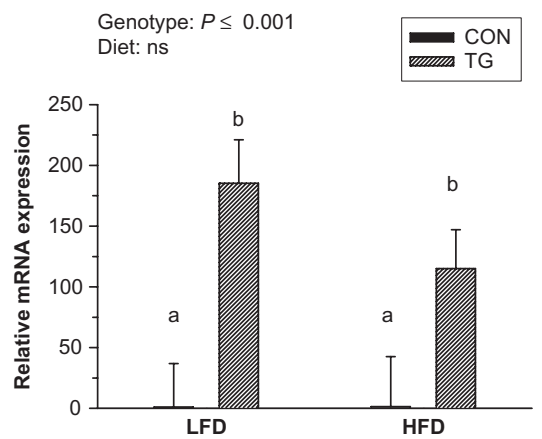

Figure 6 Skeletal muscle mRNA expression of IL- I5 receptor subunits following 20 weeks of low-fat diet (LFD) or high-fat diet (HFD) regimens in control (CON) and IL-I5 $\mathrm{Tg}(\mathrm{TG})$ mice. Relative mRNA expression in each panel represents fold difference relative to LFD CON value. A, B) Soleus and extensor digitorum longus (EDL) expression of IL-15 receptor-alpha (IL-15R $\alpha$ ). C, D) Soleus and EDL expression of IL-2 receptor-gamma (IL-2R $\gamma$ ). E, F) Soleus and EDL expression of IL-2 receptor-beta (IL-2R $\beta$ ). Bars represent mean \pm SEM. Significance of main genotype $\times$ diet effects was determined by 2 -way ANOVA. No significant interactions between diet and genotype were noted for any parameter. Bars with different superscripts are significantly different $(P<0.05)$ by post-hoc analyses. Abundance of each mRNA species was comparable in CON soleus and EDL. Abundance of IL-2R $\beta$ was approximately 100 times lower than that of IL-2R $\gamma$ in CON muscles.

Differences from our findings could be due to species differences, the muscle(s) chosen for analysis, or the chronic versus short-term nature of IL-15 administration. Likewise, SIRT1 can stimulate mitochrondrial biogenesis, ${ }^{42,43}$ but we observed no change in the percentage of SDH+ fibers in IL-15 Tg muscles. However, as we did not measure SDH staining intensity nor perform direct assays of mitochondrial density, and whether IL-15 Tg mice exhibit increased skeletal muscle mitochondrial content could not be determined.
The effects of IL-15 on skeletal muscle mass remain unclear. In vitro, IL-15 overexpression causes skeletal muscle hypertrophy via stimulation of protein synthesis and inhibition of protein degradation. ${ }^{18}$ In this study and others using healthy, young rodents, no effect of IL-15 on overall lean body mass was observed. ${ }^{19,22,33,51}$ However, the present study and others ${ }^{19,33,51}$ have shown small, but significant increases in soleus muscle mass in response to IL-15 administration, but no effect on mass of mixed or glyolytic muscles. These findings suggest 
that he effects of IL-15 on oxidative and glycolytic muscles may differ. In as much as oxidative muscle fibers are smaller, a shift from glycolytic to oxidative fiber types may mask relative hypertrophy of oxidative fibers and result in no apparent effects on overall muscle mass. ${ }^{52}$ We observed no differences between IL-15 Tg and control mice in mean muscle fiber diameters (not shown), but our analysis did not distinguish different types of muscle fibers. We explored the possibility that chronic overexpression of IL-15 caused muscle tissue to downregulate expression of one or more subunits of the IL-15 receptor. However, at the mRNA level we observed no changes in expression of the IL-15-specific subunit, IL-15R $\alpha$, moderate upregulation of IL-2R $\gamma$, and large increases in expression of the relatively rare IL- $2 \mathrm{R} \beta$ transcript. The significance of the upregulation of these specific IL-15 receptor mRNA species is unclear, but in general these data do not support the idea that constitutive IL-15 overexpression induces downregulation of IL-15 receptor subunits, which could result in a paradoxical muscle insensitivity to IL-15. Additionally, differences in expression of IL-15 receptor subunit mRNA between the soleus and EDL were not observed.

Reports on the effects of IL-15 on muscles which are wasting or degenerating are also conflicting. IL-15 preserves muscle mass and inhibits muscle nuclear apoptosis in rodent models of cancer cachexia ${ }^{33,51}$ and increases muscle fiber diameter and strength in muscular dystrophic mice. ${ }^{53}$ Increased IL-15 expression correlates with preservation of muscle mass and decreases in markers of apoptosis in aging calorie-restricted rats. ${ }^{54}$ However, another study indicated that administration of human recombinant IL-15 to rats decreased muscle mass and stimulated muscle nuclear apoptosis, particularly in aged rats. ${ }^{34}$ The basis for the differences among these studies is unclear, but may correlate with differences in energy availability in the various models. Our study implicated modulation of SIRT1 expression and oxidative skeletal muscle metabolism in IL-15 action. SIRT1 activation is involved in numerous biological processes, including prolongation of lifespan via calorie restriction, inhibition of apoptosis, protection from insulin resistance, and mediation of a switch from glyclolytic to oxidative muscle metabolism in low-energy conditions. ${ }^{55}$ However, SIRT1 also inhibits muscle differentiation and myofibrillar protein expression. ${ }^{56,57}$ Therefore, if stimulation of SIRT1 activity is part of the mechanism of IL-15 action, the modulation of SIRT1 activity in different metabolic conditions and its negative effect on myogenesis could explain the variable effects of IL-15 in different in vitro and in vivo models.
In summary, our findings suggest that IL-15 regulates oxidative skeletal muscle metabolism, which in turn could modulate body composition and insulin sensitivity. Inasmuch as IL-15 plays a role in innate immunity, IL-15-induced physiological modulations may function as part of the conversion to oxidative metabolism which takes place in response to physiological stress. ${ }^{35,44,56}$ Further work is necessary in order to define the biochemical mechanism of IL-15 action, and to examine the relative contributions of skeletal muscle and other metabolic tissues to IL-15-induced changes in body composition. Nevertheless, correlative reports on IL-15 in human subjects ${ }^{20,21,25,30,49}$ suggest that our findings are applicable to human medical applications. Therefore, modulation of IL-15 signaling may have therapeutic potential to modulate body composition and insulin sensitivity.

\section{Acknowledgments}

Supported by NIH grant \#RO1AG024136 from the National Institute on Aging to LSQ, the Transgenic Animal Model Development Core of the University of Washington Nathan Shock Center of Excellence in the Basic Biology of Aging (NIH grant \#5P30AG013280), the Molecular Genetics Core of the University of Washington Diabetes Endocrinology Research Center (NIH grant \# 5P30DK17047), Seattle Institute for Biomedical and Clinical Research, and by use of resources and facilities at the VA Puget Sound Health Care System, Seattle, WA. EEP was supported by an NIH training grant in Muscle Biology (AR053461) through the Pennsylvania Muscle Institute, Philadelphia, PA. Dr Rebecca Hull and Melissah Watts, VA Puget Sound Health Care System, provided valuable technical advice on ITTs.

\section{Disclosure}

The authors report no conflicts of interest.

\section{References}

1. Hill JA, Wyatt HR, Reed GW, Peters JC. Obesity and the environment: where do we go from here? Science. 2003;299(5608):853-855.

2. Kahn SE, Hull RL, Utzschneider KM. Mechanisms linking obesity to insulin resistance and type 2 diabetes. Nature. 2006;444(7121):840-846.

3. Harris MI, Flegal KM, Cowie CC, et al. Prevalence of diabetes, impaired fasting glucose, and impaired glucose tolerance in US adults. Diabetes Care. 1998;21(4):518-524.

4. Goodpaster BH, Wolf D. Skeletal muscle lipid accumulation in obesity, insulin resistance, and type 2 diabetes. Pediat Diabetes. 2004;5(4):219-226.

5. Petersen KF, Befroy D, Dunfour S, et al. Mitochondrial dysfunction in the elderly: possible role in insulin resistance. Science. 2003;300(5622):1140-1142.

6. Wolf G. Role of fatty acids in the development of insulin resistance and type 2 diabetes mellitus. Nutrit Rev. 2008;66(10):597-600. 
7. Srikanthan P, Hevener AL, Karlamangla AS. Sarcopenia exacerbates obesity-associated insulin resistance and dysglycemia: findings from the National Health and Nutrition Examination Survey III. PLoS One. 2010;5(5):e10805.

8. Trujillo ME, Scherer PE. Adipose tissue-derived factors: impact on health and disease. Endocrine Rev. 2006;27(7):762-778.

9. Pedersen BK. The diseasome of physical inactivity - and the role of myokines in muscle-fat crosstalk. J Physiol. 2009;587(23):5559-5568.

10. Hotamsligil GS, Shargill NS, Spiegelman BM. Adipose expression of tumor necrosis factor-alpha: direct role in obesity-linked insulin resistance. Science. 1993;259(5091):87-91.

11. Reid MB, Li YP. Tumor necrosis factor-alpha and muscle wasting: a cellular perspective. Resp Res. 2001;2(5):269-272.

12. Visser M, Pahor M, Taaffe DR, et al. Relationship of interleukin-6 and tumor necrosis factor- $\alpha$ with muscle mass and muscle strength in elderly men and women: the Health ABC Study. $J$ Gerontol. 2002;57A(5):M326-M332.

13. Krause MP, Liu $\mathrm{Y}, \mathrm{Vu} \mathrm{V}$, et al. Adiponectin is expressed by skeletal muscle fibers and influences muscle phenotype and function. $\mathrm{Am} \mathrm{J}$ Physiol. 2008;295(1):C203-C212.

14. Liu Y, Chewchuk S, Lavigne C, et al. Functional significance of skeletal muscle adiponectin production, changes in animal models of obesity and diabetes, and regulation by rosiglitazone treatment. Am J Physiol. 2009;297(3):E657-E664.

15. Maeda N, Takahashi M, Funahashi T, et al. PPAR $\gamma$ ligands increase expression and plasma concentrations of adiponectin, an adiposederived protein. Diabetes. 2001;50(9):2094-2099.

16. Grabstein KH, Eisenman J, Shanebeck K, et al. Cloning of a T cell growth factor that interacts with the beta chain of the interleukin-2 receptor. Science. 1994;264(5161):965-968.

17. Fehniger TA, Caligiuri MA. Interleukin-15: Biology and relevance to human disease. Blood. 2001;97(4):14-32.

18. Quinn LS, Anderson BG, Drivdahl RH, Alvarez B, Argilés JM. Overexpression of interleukin-15 induces skeletal muscle hypertrophy in vitro: implications for treatment of muscle wasting disorders. Exp Cell Res. 2002;280(1):55-63.

19. Carbó N, López-Soriano J, Costelli P, et al. Interleukin-15 mediates reciprocal regulation of adipose and muscle mass: a potential role in body weight control. Biochim Biophys Acta. 2001;1526(1): $17-24$.

20. Nielsen AR, Hojman P, Erikstrup C, et al. Association between interleukin-15 and obesity: Interelukin-15 as a potential regulator of fat mass. J Clin Endo Metab. 2008;93(11):4486-4493.

21. Barra N, Reid S, MacKenzie R, et al. Interleukin-15 contributes to the regulation of murine adipose tissue and human adipocytes. Obesity. 2010;18(8):1601-1607.

22. Quinn LS, Anderson BG, Strait-Bodey L, Stroud AM, Argilés JM. Oversecretion of interleukin- 15 from skeletal muscle reduces adiposity. Am J Physiol. 2009;296(1):E191-E202.

23. Busquets S, Figueras M, Almendro V, López-Soriano FJ, Argilés JM. Interleukin-15 increases glucose uptake in skeletal muscle. An antidiabetogenic effect of the cytokine. Biochim Biophys Acta. 2006;1760(11): 1613-1617.

24. Quinn L, Strait-Bodey L, Anderson BG, Argilés JM, Havel PJ. Interleukin-15 stimulates adiponectin secretion by 3T3-L1 adipocytes: evidence for a skeletal muscle-to-fat signaling pathway. Cell Biol Internat. 2005;29(6):449-457.

25. Pistilli EE, Devaney JM, Gordish-Dressman H, et al. Interelukin-15 and interleukin-15R alpha SNPs and associations with muscle, bone, and predictors of the metabolic syndrome. Cytokine. 2008;43(1): 45-53.

26. Quinn LS, Haugk KL, Grabstein KH. Interleukin-15: a novel anabolic cytokine for skeletal muscle. Endocrinol. 1995;136(8):3669-3672.

27. Ajuwon KM, Spurlock ME. Direct regulation of lipolysis by interleukin-15 in primary pig adipocytes. Am J Physiol. 2004;287(3): R608-R611.
28. Bulfone-Paus S, Bulanova E, Pohl T, et al. Death deflected: IL-15 inhibits TNF- $\alpha$-mediated apoptosis in fibroblasts by TRAF2 recruitment to the IL-15R $\alpha$ chain. FASEB J. 1999;13(12):1575-1585.

29. Budagian V, Bulanova E, Paus R, Bulfone-Paus S. IL-15/IL-15 receptor biology: a guided tour through an expanding universe. Cytok Growth Factor Rev. 2006;17(4):259-280.

30. Wang K, Li W-D, Glessner JT, Grant SFA, Hakonarson H, Price RA. Large copy-number variations are enriched in cases with moderate to extreme obesity. Diabetes. 2010;59(10):2690-2694.

31. Alvarez B, Carbó N, López-Soriano J, et al. Effects of interleukin-15 (IL-15) on adipose tissue mass in rodent obesity models: Evidence for direct IL-15 action on adipose tissue. Biochim Biophys Acta. 2002; 1570;1:33-37.

32. Almendro V, Busquets S, Ametller E, et al. Effects of interleukin-15 on lipid oxidations: disposal of an oral [(14)C]-triolein load. Biochim Biophys Acta. 2006;1761(1):37-42.

33. Carbó N, López-Soriano J, Costelli P, et al. IL-15 antagonizes muscle protein waste in tumour-bearing rats. Brit J Cancer. 2000;83(4): 526-531.

34. Pistilli EE, Alway SE. Systemic elevation of interleukin-15 in vivo promotes apoptosis in skeletal muscles of young adult and aged rats. Biochem Biophys Res Commun. 2008;373:20-24.

35. Cantó C, Jiang LQ, Deshmukh AS, et al. Interdependence of AMPK and SIRT1 for metabolic adaptation to fasting and exercise in skeletal muscle. Cell Metab. 2010;11(3):213-219.

36. Tinsley FC, Taicher GZ, Heiman ML. Evaluation of a quantitative magnetic resonance method for mouse whole body composition analysis. Obesity Res. 2004;12(1):150-160.

37. McGuinness OP, Ayala JE, Laughlin MR, Wasserman DH. NIH experiment in centralized mouse phenotyping: the Vanderbilt experience and recommendations for evaluating glucose homeostasis in the mouse. $\mathrm{Am}$ J Phys. 2009;297(4):E849-E855.

38. Hull RL, Adrikopoulos S, Verchere CB, et al. Increased dietary fat promotes islet amyloid formation and $\beta$-cell secretory dysfunction in a transgenic mouse model of islet amyloid. Diabetes. 2003;52(2): 372-379.

39. Marshall BA, Mueckler MM. Differential effects of GLUT-1 or GLUT-4 overexpression on insulin responsiveness in transgenic mice. Am J Physiol. 1994;267(5 Pt 1):E738-E744.

40. Degens H, Turek Z, Hoofd LJ, Van't Hof MA, Binkhorst RA. The relationship between capillarisation and fibre types during compensatory hypertrophy of the plantaris muscle in the rat. JAnat. 1992;180(3): 455-463.

41. Lee C-H, Olson P, Evans RM. Minireview: Lipid metabolism, metabolic diseases, and peroxisome proliferator-activated receptors. Endocrinology. 2003;144(6):2201-2207.

42. Nasrin N, Wu X, Fortier E, et al. SIRT4 regulates fatty acid oxidation and mitochoncrial gene expression in liver and muscle cells. $J$ Biol Chem. 2010;285(42):31995-32002.

43. Gerhart-Hines Z, Rodgers JT, Baré O, et al. Metabolic control of muscle mitochondrial function and fatty acid oxidation through SIRT1/PGC1 $\alpha$. EMBO J. 2007;26(7):1913-1923.

44. Feige JN, Lagouge M, Canto C, et al. Specific SIRT1 activation mimics low energy levels and protects against diet-induced metabolic disorders by enhancing fat oxidation. Cell Metab. 2008;8(5):347-358.

45. Lin J, Wu H, Tarr PT, et al. Transcriptional co-activator PGC- $1 \alpha$ drives the formation of slow-twitch muscle fibers. Nature. 2002;418(6899): 797-801.

46. Arany Z, Lebrasseur N, Morris C, et al. The transcriptional coactivator PGC- $1 \beta$ drives the formation of oxidative type IIX fibers in skeletal muscle. Cell Metab. 2007;5(1):35-46.

47. Chan CB, Harper M-E. Uncoupling proteins: Role in insulin resistance and insulin insufficiency. Curr Diabetes Rev. 2006;2(3): $271-283$.

48. Nagy TR, Blaylock ML, Garvey WT. Role of UCP2 and UCP3 in nutrition and obesity. Nutrition. 2004;20(1):139-144. 
49. Di Renzo L, Bigioni M, Bottini FG, et al. Normal Weight Obese syndrome: role of single nucleotide polymorphism of IL-15R $\alpha$ and MTHFR $677 \rightarrow$ T genes in the relationship between body composition and resting metabolic state. Eur Rev Med Pharm Sci. 2006;10(5): 235-245.

50. Wu Z, Puigserver P, Andersson U, et al. Mechanisms controlling mitochondrial biogenesis and respiration through the thermongenic coactivator PGC-1. Cell. 1999;98(1):115-124.

51. Figueras M, Busquets $\mathrm{S}$, Carbo N, et al. Interleukin-15 is able to suppress the increased DNA fragmentation associated with muscle wasting in tumour-bearing rats. FEBS Lett. 2004;569(1-3):201-206.

52. Hughes SM, Chi MM-Y, Lowry OH, Gundersen K. Myogenin induces a shift of enzyme activity from glycolytic to oxidative metabolism in muscles of transgenic mice. J Cell Biol. 1999;145(3):633-642.

53. Harcourt LJ, Holmes AG, Gregorevic P, et al. Interleukin-15 administration improves diaphragm muscle pathology and function in dystrophic $m d x$ mice. Am J Pathol. 2005;166(4):131-141.
54. Marzetti E, Carter CS, Wohlgemuth SE, et al. Changes in IL-15 expression and death-receptor apoptotic signaling in rat gastrocnemius muscle with aging and life-long calorie restriction. Mech Aging Devel. 2009;130(4):272-280.

55. Vinciguerra M, Fulco M, Ladurner A, Sartorelli V, Rosenthal N. SirT1 in muscle physiology and disease: lessons from mouse models. Disease Models Mech. 2010;3(5-6):298-303.

56. Fulco M, Schiltz RL, Iezzi S, et al. Sir2 regulates skeletal muscle differentiation as a potential sensor of the redox state. Molec Cell. 2003;12(1):51-62.

57. Fulco M, Cen Y, Zhao P, et al. Glucose restriction inhibits skeletal myoblast differentiation by activating SIRT1 through AMPK-mediated regulation of Nampt. Devel Cell. 2008;14(5):661-673.

\section{Publish your work in this journal}

The International Journal of Interferon, Cytokine and Mediator Research is an international, peer-reviewed, open-access, online journal. The focus of the journal is to publish original research, reports, editorials, reviews and commentaries on all aspects of interferon, cytokine and mediators of inflammation from laboratory science to therapeutic indications and clinical studies. The manuscript management system is completely online and includes a very quick and fair peer-review system, which is all easy to use. Visit http://www.dovepress.com/testimonials.php to read real quotes from published authors.

Submit your manuscript here: http://www.dovepress.com/international-journal-of-interferon-cytokine-and-mediator-research-journal 